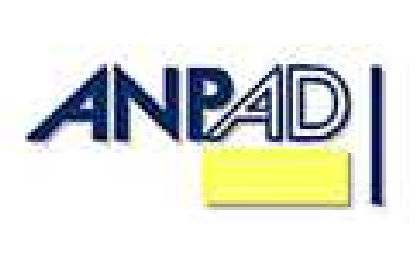

Disponível em

http://www.anpad.org.br/rac

RAC, Rio de Janeiro, v. 17, n. 1, art. 5, pp. 83-105, Jan./Fev. 2013

$(\mathrm{cc})$ EY-NO

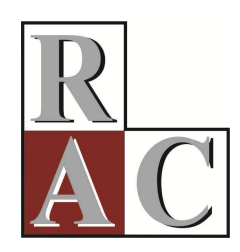

\title{
Evidências do Entendimento de Quatro Pronunciamentos Contábeis por Auditores Independentes do Brasil
}

\author{
Evidence of How Independent Brazilian Auditors Interpret Four Brazilian Accounting \\ Pronouncements
}

\author{
Neirilaine Silva de Almeida * \\ E-mail: neiresa@gmail.com \\ Universidade Federal de Uberlândia - UFU \\ Uberlândia, MG, Brasil. \\ Sirlei Lemes \\ E-mail: sirlemes@uol.com.br \\ Universidade Federal de Uberlândia - FACIC/UFU \\ Uberlândia, MG, Brasil.
}

\footnotetext{
* Endereço: Neirilaine Silva de Almeida

Universidade Federal de Uberlândia, Av. João Naves de Ávila, 2121, Campus Santa Mônica, Uberlândia/MG, 38400-902.
} 


\title{
Resumo
}

O emprego de um padrão internacional nas demonstrações contábeis das empresas do mundo tem sido cada vez mais requerido. Todavia a preocupação de autores quanto à efetiva comparabilidade das informações em função da possibilidade de interpretações díspares mesmo com o uso de normas idênticas, ainda persiste. Assim, este estudo tem o objetivo de identificar quais são as interpretações dos auditores independentes no que concerne a quatro Pronunciamentos Contábeis brasileiros, por meio de um questionário adaptado de Chand, Patel e Patel (2010). Ademais, buscou-se identificar a associação entre as interpretações dos auditores e quatro variáveis (tamanho da empresa; familiaridade com as IFRS; experiência com auditoria; e experiência com as IFRS). Para tanto, o Teste Qui-quadrado, a ANACOR e a HOMALS foram aplicados. Como resultado, verificou-se a falta de consenso nas respostas dos auditores da amostra. Observou-se, ainda, que as interpretações de três Pronunciamentos Contábeis foram estatisticamente distintas, em função do tamanho da empresa ou da familiaridade com as IFRS ou, ainda, do tempo de experiência com atividades relacionadas às IFRS. À luz desses resultados, infere-se que, diante do uso de uma mesma norma, existe a possibilidade de que os profissionais efetuem interpretações distintas que resultem em relatórios contábeis não comparáveis.

Palavras-chave: pronunciamentos contábeis; entendimento das normas; auditores independentes.

\begin{abstract}
The employment of an international standard for corporate financial statements worldwide has been increasingly required. However the concern some authors have as to effective comparability of information, depending on the possibility of disparate interpretations even with the use of identical standards, still persists. Thus, this study aims to identify how independent auditors of companies indexed in the CVM interpret four Brazilian Accounting Pronouncements, by means of a questionnaire adapted from Chand, Patel and Patel (2010). In addition, the research attempts to identify the association between the auditors' interpretations and four variables (the size of the undertaking; familiarity with IFRS; experience with auditing; and experience with IFRS-related activities). Analysis was done via Chi-square Test, Correspondence Analysis (ANACOR) and Homogeneity Analysis (HOMALS). The results show a lack of consensus among auditors in the sample. It was noticed that interpretations of the three Brazilian Accounting Pronouncements were statistically distinct in function: the size of the undertaking, familiarity with IFRS, and experience with IFRS-related activities. In light of these results, it can be inferred that, within the use of the same standard, there is a possibility that Brazilian professionals have different interpretations and, therefore, make decisions that will produce non-comparable accounting reports.
\end{abstract}

Key words: international financial reporting standards; interpretation of standards; independent auditors. 


\section{Introdução}

A literatura referente à Ciência Contábil, outrora voltada para as regras pertinentes a especificidades de cada país, viu-se diante de um novo cenário, que culminou com os anseios de investidores e profissionais contábeis, dentre outros interessados, por normas que atenuassem as divergências dos díspares padrões contábeis intrínsecos a cada nação e promovessem benefícios como a comparabilidade das informações financeiras (Carvalho, Lemes, \& Costa, 2008; Niyama, 2008).

A criação do International Accounting Standards Board (IASB) e a determinação da elaboração das demonstrações consolidadas, das empresas listadas nas bolsas de valores dos países da União Europeia, em consonância com as International Financial Reporting Standards (IFRS), a partir de 2005, foram acontecimentos significativos para impulsionar a convergência dos países aos padrões internacionais (Baker \& Barbu, 2007; Schmidt, Santos, \& Fernandes, 2004).

De fato, conforme dados do IASB (2012), aproximadamente 120 países já seguem essas normas contábeis. O Brasil, por exemplo, alcançou progressos com a criação do Comitê dos Pronunciamentos Contábeis (CPC), com a promulgação da Lei $\mathrm{n}^{\circ} 11.638$, de 28 de dezembro de 2007, e, com a obrigatoriedade, a partir de 2010, das demonstrações consolidadas de determinadas entidades do país, como as companhias de capital aberto e as empresas sob a égide do Banco Central do Brasil (BACEN) e da Superintendência de Seguros Privados (SUSEP), serem apresentadas em conformidade com as normas emitidas pelo CPC.

Nesse cenário, em que as IFRS estão sendo adotadas nos países, é oportuno o realce da responsabilidade e da qualificação dos contabilistas que estão aplicando essas normas, uma vez que muitas destas contêm preceitos divergentes dos que esses profissionais empregavam, como a aplicação do custo atribuído no Brasil, além de expressões e instruções complexas, como os julgamentos ancorados nas palavras provável, remota, substancialmente, entre outras encontradas no Padrão Internacional, que podem gerar incertezas, em relação aos procedimentos que devem ser adotados para $\mathrm{o}$ assertivo atendimento das normas.

Assim, diante dessas possíveis incertezas, se os profissionais contábeis interpretarem as normas de formas divergentes, a comparabilidade das informações financeiras, almejada pela convergência dos padrões contábeis dos países às IFRS, pode não ser alcançada com eficácia (Chand, Patel, \& Day, 2008; Doupnik \& Richter, 2003).

O problema inerente à interpretação das normas também está fundamentado na opinião de alguns autores, como Fogarty, Hussein e Ketz (1994), Nobes (2006) e Alali e Cao (2010), que discorrem que, diante da ocorrência de distintas interpretações das IFRS, as demonstrações financeiras, que deveriam ser comparáveis entre os países, poderiam ser vistas como pouco confiáveis e, consequentemente, perder a credibilidade no cenário mundial.

Nesse mesmo âmbito, respeitada a relevância dos contabilistas, ressalta-se a função do auditor nesse processo. $\mathrm{O}$ valor atribuído a esse profissional é justificado por sua responsabilidade de verificar, formar uma opinião e atestar que as demonstrações financeiras das empresas estão concernentes com as normas vigentes, visando proteger os interesses dos investidores e preservar a credibilidade do mercado (Niyama \& Silva, 2009).

Ainda no tocante ao ofício desses profissionais, Chand, Patel e Patel (2010) avaliaram as interpretações dos auditores das Ilhas Fiji diante de cenários relacionados aos custos de empréstimos de uma construtora, aos tributos diferidos de uma companhia aérea com prejuízos fiscais, à amortização do Goodwill e aos custos com pesquisa e desenvolvimento de uma empresa agrícola. De forma geral, os autores constataram que as interpretações foram afetadas pelo tamanho da empresa em que os auditores trabalhavam. 
Com base nos resultados identificados por Chand et al. (2010) em Fiji, emerge o interesse de identificar como os auditores brasileiros interpretam quatro Pronunciamentos Contábeis emitidos pelo CPC, que, com base no estudo desses autores, referem-se: ao CPC 20 - Custos de Empréstimos; ao CPC 32 - Tributos sobre o Lucro; ao CPC 25 - Provisões, Passivos Contingentes e Ativos Contingentes; e ao CPC 04 - Ativo Intangível.

Sendo assim, este estudo busca responder à seguinte questão: Quais são as interpretações dos auditores, das empresas de auditoria independente cadastradas na CVM, no que tange ao teor de quatro Pronunciamentos Contábeis emitidos pelo CPC?

De forma geral, as pesquisas anteriores têm verificado a associação entre as atividades dos auditores e algumas variáveis, como o tamanho da empresa de auditoria em que o profissional trabalha (por exemplo: Chand, Patel, \& Patel, 2010; Tsalavoutas \& Evans, 2010), a familiaridade com a atividade desempenhada (por exemplo: Chand et al., 2010) e a experiência profissional (por exemplo: Bonner, 1990; Bhattacharjee \& Moreno, 2002).

Especificamente, alguns estudos, como o de Samaha e Hegazy (2010), apontaram diferenças entre as práticas e as interpretações dos profissionais das empresas denominadas Big Four (Ernst \& Young, KPMG, PriceWaterhouseCoopers, Deloitte \& Touche) e dos auditores das demais empresas de auditoria.

No que tange à familiaridade com o tema, Bonner (1994 como citado em Chand et al., 2010) considera que as pessoas que detêm maiores níveis de conhecimentos sobre as informações necessárias para o desenvolvimento das tarefas tendem a executá-las de forma mais precisa do que os profissionais que têm menores níveis de conhecimentos, ou seja, que são menos familiarizados com o assunto.

Chand, Patel e Day (2008), por sua vez, discorreram que a experiência profissional dos envolvidos no processo de convergência contábil também pode estar relacionada com a aplicação uniforme do Padrão Internacional. Em outras palavras, eles afirmaram que o tempo de experiência poderia contribuir para a existência de diferentes práticas contábeis entre os países, mesmo com a utilização de normas comuns (Chand et al., 2008).

Diante dessas considerações, assume-se, como hipóteses nulas (H0), que as variáveis: tamanho da empresa; familiaridade; experiência profissional em atividades de auditoria; e experiência em atividades relacionadas às IFRS, estão associadas com as interpretações dos auditores. Sendo assim, o objetivo geral desta pesquisa é identificar as interpretações dos auditores independentes do Brasil no que concerne ao teor de quatro Pronunciamentos contábeis emitidos pelo CPC. Os objetivos específicos, por sua vez, consistem em verificar se as interpretações dos auditores estão associadas com: (a) o tamanho da empresa; (b) a familiaridade com as IFRS; (c) a experiência em auditoria; e (d) a experiência em atividades relacionadas às Normas Internacionais de Contabilidade.

Quanto aos aspectos metodológicos, esta pesquisa consiste em um levantamento de dados e é considerada aplicada e descritiva, com abordagem quantitativa. Para averiguar a associação entre as interpretações e as variáveis abordadas, aplicou-se o Teste Qui-quadrado, além da Análise de Correspondência (ANACOR) e da Análise de Homogeneidade (HOMALS).

De forma geral, considera-se que a identificação do entendimento dos Pronunciamentos Contábeis brasileiros representa uma oportunidade relevante para a obtenção de indícios de como tais normas estão sendo interpretadas pelos auditores do país.

O trabalho é composto por cinco seções. Após esta introdução, a segunda seção versa sobre o referencial teórico que fundamenta a questão formulada, enquanto a terceira seção expõe os aspectos metodológicos. Na quarta seção, apresentam-se as análises dos resultados, e, na última, as considerações finais e sugestões para pesquisas futuras. 


\section{Referencial Teórico}

\section{Papel da auditoria}

A auditoria é considerada um "exame sistemático das demonstrações financeiras e operações com a finalidade de determinar se estão de acordo com os princípios da contabilidade geralmente aceitos" (Hoog \& Carlin, 2009, p. 54).

Tal atividade oferece vantagens, como a fiscalização dos controles internos, a contribuição com a obtenção de informações mais fidedignas sobre a situação econômico-financeira das empresas e a asseguração da veracidade das informações contidas nos relatórios (Franco \& Marra, 2001).

A área da auditoria que é incumbida de examinar os documentos contábeis das organizações é denominada auditoria independente. Esse exame é compreendido por investidores e outros interessados, como um instrumento que proporciona segurança em relação aos relatórios financeiros das entidades. Em outras palavras, os usuários valem-se da opinião desses profissionais como subsídio para as tomadas de decisões (Almeida, 2003).

No que tange às normas que regem a auditoria independente no país, a Lei $\mathrm{n}^{\circ} 4.728$, de 14 de julho de 1965, determinou, ao Conselho Monetário Nacional (CMN), a responsabilidade de expedir normas referentes às atividades dos auditores independentes que prestassem serviços no mercado de capitais.

Na década seguinte, a Lei $\mathrm{n}^{\circ}$ 6.385, de 07 de dezembro de 1976, concedeu à CVM a incumbência de emitir as normas referentes aos registros dos auditores independentes e de fiscalizar a conduta e a atuação desses profissionais. A Lei ${ }^{\circ}$ 6.404, de 15 de dezembro de 1976, por sua vez, estabeleceu a obrigatoriedade da auditoria independente para os relatórios contábeis das companhias abertas.

O Instituto dos Auditores Independentes do Brasil (IBRACON) foi instituído, em 13 de dezembro de 1971, com o intuito de representar os profissionais da área, além de promover os melhores padrões em contabilidade e em auditoria. Esse órgão é responsável pela emissão dos pronunciamentos que norteiam o ofício do auditor. Ademais, o IBRACON coopera com a convergência das normas brasileiras às Normas Internacionais de Auditoria. Como consequência desse processo, um conjunto de novas diretrizes de auditoria independente, convergentes ao Padrão Internacional, entrou em vigor em 2010 (IBRACON, 2011).

\section{Os pronunciamentos contábeis brasileiros}

O Brasil sempre teve sua contabilidade atrelada à legislação e à regulamentação por organismos governamentais (Niyama, 2008). Na última década, porém, o movimento em torno da adoção das IFRS produziu reflexos na área contábil brasileira. A criação do CPC, em 2005, por exemplo, com o objetivo de cuidar dos assuntos referentes aos Pronunciamentos Técnicos inerentes à convergência da contabilidade brasileira aos padrões internacionais, foi um avanço considerável no país.

Dentre os Pronunciamentos emitidos pelo CPC, destacam-se, brevemente, alguns aspectos do CPC 20 - Custos de Empréstimos, do CPC 32 - Tributos sobre o Lucro, do CPC 25 - Provisões, Passivos Contingentes e Ativos Contingentes, e do CPC 04 - Ativo Intangível, que fundamentam o instrumento utilizado nesta pesquisa.

O CPC 20 estabelece que as empresas contabilizem os custos de empréstimos inerentes à aquisição, à construção ou à produção de ativo qualificável como parte do custo dos ativos (CPC, 2009a). A capitalização dos custos de empréstimos deve iniciar quando ocorrerem esses custos, os gastos para a obtenção do ativo e as atividades necessárias para o seu preparo. Essa capitalização deve ser suspensa quando as atividades de desenvolvimento do ativo forem interrompidas por longos 
períodos. Algumas exceções ocorrem em ocasiões nas quais substancial trabalho técnico e administrativo continua sendo executado ou quando um atraso temporário é uma parte inevitável no processo de conclusão do ativo, como, por exemplo, os eventos ambientais rotineiros do local (CPC, 2009a).

A finalização da capitalização, por sua vez, deve ocorrer "quando substancialmente todas as atividades necessárias ao preparo do ativo qualificável para seu uso ou venda pretendidos estiverem concluídas" (CPC, 2009a, pp. 6-7). A exemplificação do Pronunciamento mostra que uma propriedade que exija apenas modificações menores, como as atividades referentes à decoração, pode ser considerada como substancialmente pronta. Assim, nas palavras da Farah e Ricardino (2010, p. 248), a alocação de custos de empréstimos no ativo deve findar quando faltarem "pequeníssimos acabamentos".

Ademais, a capitalização dos custos de empréstimos referentes aos ativos concluídos em partes deve cessar "quando completar substancialmente todas as atividades necessárias ao preparo daquela parte para seu uso ou venda pretendidos" (CPC, 2009a, p. 7).

Em suma, as empresas devem capitalizar os custos de empréstimos, pertinentes aos ativos qualificáveis, e mudar esse tratamento contábil quando os ativos estiverem substancialmente prontos para uso ou venda. A inquietação pertinente a essa questão reside na possibilidade de díspares julgamentos referentes à palavra substancialmente, o que poderia acarretar diferentes tratamentos contábeis nas empresas, mesmo com a utilização de uma mesma norma.

Já o CPC 32 - Tributos sobre o Lucro, tem o objetivo de delinear a contabilização dos ativos fiscais diferidos, o reconhecimento e a apresentação dos tributos sobre o lucro, bem como a divulgação das informações relacionadas a eles (CPC, 2009b).

Um dos pontos tratados no CPC 32 refere-se à contabilização das diferenças temporárias tributáveis e das diferenças temporárias dedutíveis, que são consideradas as diferenças entre os valores contábeis de um ativo ou passivo e os seus valores para o cálculo de impostos (base fiscal). De forma geral, os passivos fiscais diferidos são reconhecidos para as diferenças temporárias tributáveis, enquanto os ativos fiscais diferidos são os valores concernentes às diferenças temporárias dedutíveis e ao transporte de prejuízos e créditos fiscais não utilizados (CPC, 2009b).

Assim, esses ativos fiscais são reconhecidos para todas as diferenças temporárias dedutíveis, prejuízos fiscais e créditos fiscais não utilizados quando for provável a existência de lucros tributáveis contra os quais as diferenças temporárias dedutíveis e os prejuízos ou créditos fiscais não utilizados possam ser aproveitados (CPC, 2009b). Para identificar a probabilidade da disponibilidade de lucro tributável no futuro, contra o qual os prejuízos fiscais ou créditos fiscais possam ser utilizados, a empresa deve averiguar várias premissas, como, por exemplo, "se é provável que a entidade terá lucros tributáveis antes que os prejuízos fiscais ou créditos fiscais não usados expirem" (CPC, 2009b, p. 18).

Se todas as premissas não forem atendidas, o ativo fiscal diferido não é reconhecido. Todavia a empresa deve atentar para a possibilidade da contabilização futura dos ativos fiscais diferidos não reconhecidos. Em outras palavras, caso se torne provável que a empresa terá lucros tributáveis disponíveis no futuro, ela poderá reconhecer tal ativo (CPC, 2009b).

De forma geral, observa-se a necessidade de julgamentos para a determinação do quão provável será a existência de lucros tributáveis disponíveis no futuro, uma vez que isso é vital para o reconhecimento ou não de ativos e passivos fiscais diferidos. Por conseguinte, o acompanhamento da rentabilidade da empresa é uma tarefa importante, por exemplo, para identificar a necessidade de uma possível baixa dos ativos fiscais diferidos.

O CPC 25 - Provisões, Passivos Contingentes e Ativos Contingentes, por sua vez, expõe que o passivo é uma obrigação presente, oriunda de um evento passado, que resulta em uma saída de 
recursos da entidade, enquanto a provisão, apesar de ser um passivo, possui características incertas quanto ao seu prazo e valor, e deve ser reconhecida apenas nos casos em que:

(a) a entidade tem uma obrigação presente (legal ou não formalizada) como resultado de um evento passado; (b) seja provável que será necessária uma saída de recursos que incorporam benefícios econômicos para liquidar a obrigação; e (c) possa ser feita uma estimativa confiável do valor da obrigação (CPC, 2009c, p. 7).

Um evento que gera obrigações presentes ocorre quando: a liquidação da obrigação pode ser imposta legalmente; ou no caso de uma obrigação não formalizada, originada pela criação de expectativas de que a entidade cumprirá o seu dever (CPC, 2009c).

Além de verificar a existência de uma obrigação presente, é necessário identificar a probabilidade de saída de recursos. Para tanto, o Pronunciamento pondera que uma saída de recursos é provável quando é mais afirmativo do que negativo que o desembolso irá ocorrer. Em outras palavras, Nannini e Salotti (2010, p. 363) consideram que "qualquer coisa acima de 50\% de chance de ocorrer" deve ser considerada como provável para o reconhecimento das provisões de obrigações, o que realça a essencialidade das estimativas contábeis.

A terceira característica da provisão diz respeito à necessidade de estimativas suficientemente confiáveis. Especificamente, as provisões são reconhecidas contabilmente, pois são obrigações presentes, cujas saídas de recursos são prováveis. Já os passivos contingentes não são reconhecidos como passivos e sim evidenciados em notas explicativas, pois são obrigações, cujas saídas de recursos ainda necessitam ser confirmadas ou não são prováveis ou, ainda, não podem ser estimadas com confiança (CPC, 2009c).

Por fim, o CPC 04 - Ativo Intangível esclarece que, para que os ativos intangíveis sejam reconhecidos, é necessário que seja provável que existirão benefícios econômicos futuros em favor da entidade e que o custo do ativo possa ser mensurado com confiabilidade.

Dentre esses ativos, verifica-se uma complexidade no que diz respeito ao reconhecimento do ativo intangível gerado internamente, que passa pelas fases de pesquisa e de desenvolvimento. O CPC 04 - Ativo Intangível determina que os gastos que ocorrem durante a fase de pesquisa de projeto interno devem ser registrados como despesas, uma vez que, nesse momento, a empresa ainda não consegue demonstrar que produziu um ativo intangível que proporcionará prováveis benefícios econômicos futuros.

De acordo com esse mesmo Pronunciamento, o desenvolvimento compreende a aplicação dos resultados da pesquisa ou de outros conhecimentos em um plano ou projeto visando à produção de algo, antes do início da sua produção comercial ou do seu uso. Assinala-se que, na fase de desenvolvimento, o ativo intangível resultante já está em condições de ser reconhecido (CPC 04, 2010).

A evidenciação da disponibilidade de recursos para concluir, usar e obter os benefícios gerados por um ativo intangível pode ser efetuada por meio de um plano de negócios que demonstre os recursos técnicos, financeiros e outros recursos necessários, além da capacidade da entidade de garantir tais recursos (CPC, 2010).

Assim, a dificuldade reside em verificar se os ativos gerados internamente já podem ser considerados como ativos intangíveis presentes na fase de desenvolvimento, ou se eles ainda devem ser considerados como projetos em fase de pesquisa.

\section{O entendimento das normas internacionais de contabilidade}

Considerando o processo de adoção das IFRS no mundo, ressalta-se que, mesmo que a convergência mundial vise à promoção de relatórios financeiros comparáveis entre países distintos, a 
comparabilidade das informações financeiras pode não ser alcançada apenas com a utilização de normas uniformes, pois existem outros fatores, como a forma com que os contabilistas interpretam as normas, que influenciam as demonstrações (Chand et al., 2010; Nobes, 2006; Schultz, \& Lopez, 2001).

Zeff (2007) defende que a interpretação é vital para a comparabilidade e que a cultura dos países e as questões que envolvem probabilidade podem dificultar a existência de interpretações uniformes. De fato, alguns estudos, como o de Chand et al. (2010), apontaram diferenças entre as interpretações dos profissionais das empresas denominadas Big Four, comumente citadas em função de sua qualidade e dos auditores das demais empresas de auditoria (Piot, Dumontier, \& Janin, 2010).

No que concerne à experiência nas atividades, pesquisas sobre o tema ponderaram que o tempo de experiência pode promover disparidades entre os julgamentos dos auditores novatos e dos mais experientes (por exemplo: Bhattacharjee \& Moreno, 2002; Chand et al., 2008; Choo \& Trotman, 1991).

Além disso, os julgamentos realizados por pessoas com maiores conhecimentos sobre o assunto tendem a ser diferentes dos efetuados pelos profissionais que não tenham a mesma compreensão do tema, uma vez que os contabilistas que estão familiarizados com as normas contábeis tendem a interpretá-las de forma mais consistente do que os que estão menos familiarizados (Asare \& McDaniel, 1996; Chand et al., 2010).

O fato é que, com a convergência, alguns fatores que causam essas diferenças, como o conteúdo das normas contábeis, estão sendo eliminados. Contudo, deve-se levar em conta que outras causas que contribuem para as divergências entre as nações, como os sistemas políticos e as diferenças individuais entre os contabilistas, ainda permanecem. Assim, o uso de normas comuns, embora seja um progresso, pode não ser suficiente para o alcance da efetiva comparabilidade das informações (Chand et al., 2008).

Pelo exposto, percebe-se que a adoção das IFRS, por si só, não necessariamente implica a extinção de tratamentos contábeis díspares entre os países. Assim, destaca-se a importância das interpretações para o alcance de melhor qualidade e confiabilidade das informações, bem como da comparabilidade das demonstrações financeiras.

\section{Aspectos Metodológicos}

Esta pesquisa é considerada aplicada e descritiva, com abordagem quantitativa, que visa verificar as interpretações dos auditores independentes por meio de um levantamento de dados.

Para tanto, optou-se pela aplicação de um questionário, que foi disponibilizado no formato online, por meio da ferramenta Survey Monkey, e que ficou disponível no período de 20/06/2011 a 31/08/2011. Para melhor adequação ao contexto brasileiro, após a solicitação de autorização para uso do instrumento com ajustes, efetuaram-se adaptações no questionário testado e validado pelos autores Chand et al. (2010) em um estudo com auditores de Fiji. Especificamente, o questionário é composto por duas seções, sendo que uma delas consiste na solicitação de dados qualitativos dos respondentes, que se referem à familiaridade com as Normas Internacionais de Contabilidade, à experiência em atividades de auditoria e à experiência em atividades relacionadas às IFRS, além de dados das empresas de auditoria independente em que os inquiridos trabalhavam.

A outra seção, por sua vez, trouxe explanações sobre as questões, instruções gerais sobre a forma como os auditores deveriam evidenciar as suas interpretações, além dos quatro cenários distintos, que consideraram situações práticas das rotinas dos auditores, e das normas contábeis que nortearam as decisões em cada um dos casos. 
Cada cenário apresentou uma situação e exigiu uma decisão sobre como determinada transação deveria ser contabilizada. Para tanto, cada situação incluiu a descrição de uma conversa entre dois profissionais, sendo que um afirmava que um tratamento contábil deveria ser usado, e o outro opinava que um tratamento diferenciado precisaria ser utilizado. Os respondentes apontaram as suas interpretações com base na escala Likert, decomposta em: (1) Discordo fortemente; (2) Discordo; (3) Neutro; (4) Concordo; e (5) Concordo fortemente.

Destaca-se que os auditores foram informados que, se discordassem de um contabilista, seria entendido que concordavam com o outro profissional. Dessa forma, um auditor que não concordasse com nenhum dos dois tratamentos contábeis ou que julgasse que as informações disponíveis não eram suficientes para a formação de sua opinião, teria a opção de ficar neutro. Entende-se que, assim, os auditores que concordaram ou discordaram dos tratamentos contábeis sentiram-se aptos a responder às questões. Ademais, para a atenuação de possíveis ambiguidades do instrumento, efetuaram-se prétestes com auditores e contabilistas.

Esta pesquisa abrangeu as empresas de auditoria independente cadastradas na CVM. Para tanto, por meio de consultas ao sítio dessa Comissão, no dia 20/03/2011, verificou-se a existência de 794 auditores sócios responsáveis. Desses, obteve-se o endereço eletrônico de 459 profissionais e o questionário foi respondido por 72 inquiridos.

Para o tratamento dos dados deste estudo, optou-se pela utilização do Teste Qui-quadrado, uma vez que ele avalia se duas ou mais amostras independentes diferem em determinada característica (Levine, Stephan, Krehbiel, \& Berenson, 2008).

O emprego do Teste Qui-quadrado é pertinente para o atendimento do objetivo desta pesquisa, pois, conforme Fernandes, Lima, Vieira e Niyama (2011, p. 35), tal teste tem o potencial de indicar se o "padrão de respostas (a proporção de indivíduos que responderam uma alternativa e a proporção dos sujeitos que responderam a outra opção) nos grupos analisados é significativamente diferente (se existir associação) ou não (se não for encontrada associação estatística)".

A utilização do referido teste estatístico também está em consonância com outros trabalhos da literatura contábil que, pautados em um questionário, buscaram verificar a associação entre as opiniões de respondentes com distintas características (por exemplo: Fernandes, Lima, Vieira, \& Niyama, 2011; Raimundini, Bianchi, Santos, Fávero, \& Schmidt, 2009; Souza \& Cardoso, 2012).

Para a eficácia do Teste Qui-quadrado, Levine, Stephan, Krehbiel e Berenson (2008) discorrem que, no máximo, $20 \%$ das células podem ter frequências esperadas menores que cinco, e que nenhuma célula deve possuir frequência esperada menor que um; contudo, tais premissas não foram atendidas na pesquisa. Diante desse impasse, Pavese e Forbes (2008) defendem que a técnica de Monte Carlo pode ser aplicada para o teste de homogeneidade quando o Teste Qui-quadrado não pode ser utilizado com eficácia. Assim, por intermédio do software Statistical Package for the Social Sciences (SPSS) 15.0, realizou-se o Teste Qui-quadrado e, para reforçar os resultados obtidos, também se calculou o Teste Qui-quadrado (Monte Carlo). Os níveis de significância adotados para a rejeição das hipóteses nulas da pesquisa foram de $\alpha=5 \%$ e $\alpha=10 \%$.

Nos casos em que as hipóteses nulas foram rejeitadas pelo Teste Qui-quadrado, houve a utilização de técnicas multivariadas (ANACOR e HOMALS), com o intuito de representar graficamente as associações entre as variáveis da pesquisa e as interpretações dos auditores.

A ANACOR é uma "técnica de análise de correspondência simples, destinada ao estudo da relação entre duas variáveis qualitativas" (Fávero, Belfiore, Silva, \& Chan, 2009, p. 272). Os resultados dessa análise são "as associações entre um conjunto de variáveis categóricas não métricas em um mapa perceptual, permitindo, desta maneira, um exame visual de qualquer padrão ou estrutura de dados" (Fávero et al., 2009, pp. 272 - 273).

Especificamente, Fávero, Belfiore, Silva e Chan (2009, p. 273) discorrem que: 
quando categorias de uma mesma variável encontram-se em posições próximas no mapa da análise de correspondência, isso sugere que, independentemente de seus conteúdos semânticos, elas podem ser consideradas iguais no que tange à distribuição de massas do total das observações realizadas.

Conforme referido acima, a ANACOR trata de associações de apenas duas variáveis qualitativas, o que é superado pela HOMALS. Especificamente, a HOMALS fornece subsídios para que o pesquisador avalie, simultaneamente, as relações entre duas ou mais variáveis qualitativas. Os resultados da HOMALS são representações gráficas que permitem visualizar a disposição das categorias englobadas no estudo (Fávero et al., 2009).

A HOMALS permite "analisar as relações entre todas as variáveis, de forma conjunta e simultânea, a partir de uma configuração simples e bidimensional, razão pela qual seu uso torna-se aplicável em ciências sociais" (Fávero et al., 2009, p. 291).

Sendo assim, a ANACOR pode ser aplicada em cenários em que as interpretações dos auditores apresentem associação com apenas uma variável, e a HOMALS, nos cenários em que haja a associação entre mais de uma variável e as respostas dos profissionais.

No tocante às limitações do estudo, resguardadas as vantagens do questionário, como a possibilidade de envio para muitas pessoas de diversas localizações, destaca-se a dificuldade de obtenção de retornos. Assim, esta pesquisa limitou-se pelo pequeno número de respostas, o que acarretou a impossibilidade de efetuar generalizações para o restante da população.

Ademais, as situações abordadas são simplificadas e não refletem a quantidade e a complexidade de informações existentes nos julgamentos dos auditores em sua rotina prática. Portanto, tal instrumento tem intuito acadêmico e limitou-se pela pequena quantidade de informações disponíveis e pela simplicidade.

\section{Análise dos Dados}

\section{Qualificação da amostra}

Da amostra de 72 profissionais, 69,44\% eram provenientes de empresas não Big Four e 30,56\% faziam parte do quadro de colaboradores de empresas Big Four. A maior parte desses profissionais $(80,56 \%)$ contabilizava mais de oito anos de experiência em atividades de auditoria, o que forneceu indícios de que a pesquisa apresenta informações oriundas de interpretações de profissionais com expressiva vivência prática profissional (Tabela 1).

No que tange à experiência profissional em IFRS, a amostra da pesquisa é composta por 30,55\% de auditores que atuavam há mais de cinco anos nessa área e 65,28\% que trabalhavam entre um e cinco com essas Normas (Tabela 1). 
Tabela 1

Qualificação da Amostra

\begin{tabular}{lcccc}
\hline Variáveis & Categorias & $\begin{array}{c}\text { Auditores } \\
(\text { Big Four })\end{array}$ & $\begin{array}{c}\text { Auditores (Não } \\
\text { Big Four })\end{array}$ & Percentual total \\
\hline Experiência em atividades & Até 2 anos & - & $6,00 \%$ & $4,17 \%$ \\
de auditoria & De 2 a 5 anos & - & $8,00 \%$ & $5,55 \%$ \\
& De 5 a 8 anos & $9,10 \%$ & $10,00 \%$ & $9,72 \%$ \\
& Mais de 8 anos & $90,90 \%$ & $76,00 \%$ & $80,56 \%$ \\
\cline { 2 - 5 } & Total & $\mathbf{1 0 0 \%}$ & $\mathbf{1 0 0 \%}$ & $\mathbf{1 0 0 \%}$ \\
\hline Experiência profissional & Até 1 ano & - & $6,00 \%$ & $4,17 \%$ \\
em Normas Internacionais & De 1 a 2 anos e 6 meses & $13,64 \%$ & $32,00 \%$ & $26,39 \%$ \\
& De 2 anos e 6 meses a 5 anos & $40,91 \%$ & $38,00 \%$ & $38,89 \%$ \\
\cline { 2 - 5 } & Mais de 5 anos & $45,45 \%$ & $24,00 \%$ & $30,55 \%$ \\
\hline $\begin{array}{l}\text { Nível de familiaridade } \\
\text { com as Normas }\end{array}$ & Total & $\mathbf{1 0 0 \%}$ & $\mathbf{1 0 0 \%}$ & $\mathbf{1 0 0 \%}$ \\
Internacionais & 0 a 3 & - & $2,00 \%$ & $1,39 \%$ \\
& 4 a 7 & $31,82 \%$ & $48,00 \%$ & $43,06 \%$ \\
& 8 a 10 & $68,18 \%$ & $50,00 \%$ & $55,55 \%$ \\
\hline
\end{tabular}

Percebeu-se, ainda, que a maior parte dos auditores considerou que possui familiaridade, relativamente alta, com o tema, o que forneceu indícios de que os profissionais que integram esta pesquisa detêm proximidade com as IFRS.

\section{Entendimento das normas pelos auditores independentes}

No cenário 1, os auditores se depararam com uma construtora que captou um empréstimo para construir o primeiro de três blocos de apartamentos, pertencentes a um projeto habitacional, a qual depois buscou mais recursos para subsidiar a conclusão do projeto inteiro. Antes do término das obras, a empresa já concluiu que os três blocos gerariam lucro.

Contudo, no final do exercício social, dois contabilistas que trabalhavam na construtora tinham opiniões diferentes sobre a conclusão do bloco 1. De forma específica, um contabilista assegurava: "Agora que uma parte do projeto está substancialmente concluída, nós não poderemos capitalizar os juros dos empréstimos no bloco 1". O segundo profissional, por sua vez, asseverava: "Não. Nenhuma parte do projeto foi substancialmente concluída. Sendo assim, nós continuaremos capitalizando os juros dos empréstimos nos três blocos".

Diante dessa situação, os auditores tiveram que interpretar se essa construtora deveria finalizar a capitalização dos custos de seus empréstimos no valor do primeiro bloco. Tal pronunciamento expõe que uma entidade deve parar de capitalizar os custos dos empréstimos captados, "quando completar substancialmente todas as atividades necessárias ao preparo daquela parte para seu uso ou venda pretendidos" (CPC, 2009a, p. 7).

Para o julgamento da conclusão substancial do bloco, foi divulgado que, no final do exercício social em curso, o primeiro bloco de apartamentos estava 95\% acabado, e que alguns trabalhos administrativos, o assentamento de azulejos e as instalações de lâmpadas, interruptores, chuveiros, vidraças e pequenos acessórios ainda necessitavam ser finalizados. 
É fato que o teor do CPC 20 norteia as interpretações dos profissionais ao expor que, normalmente, os ativos estão substancialmente prontos quando necessitam apenas de modificações menores, tais como a decoração de uma propriedade. Entretanto, diante dessa situação simplificada, identificou-se, praticamente, um contraste de opiniões (Figura 1).

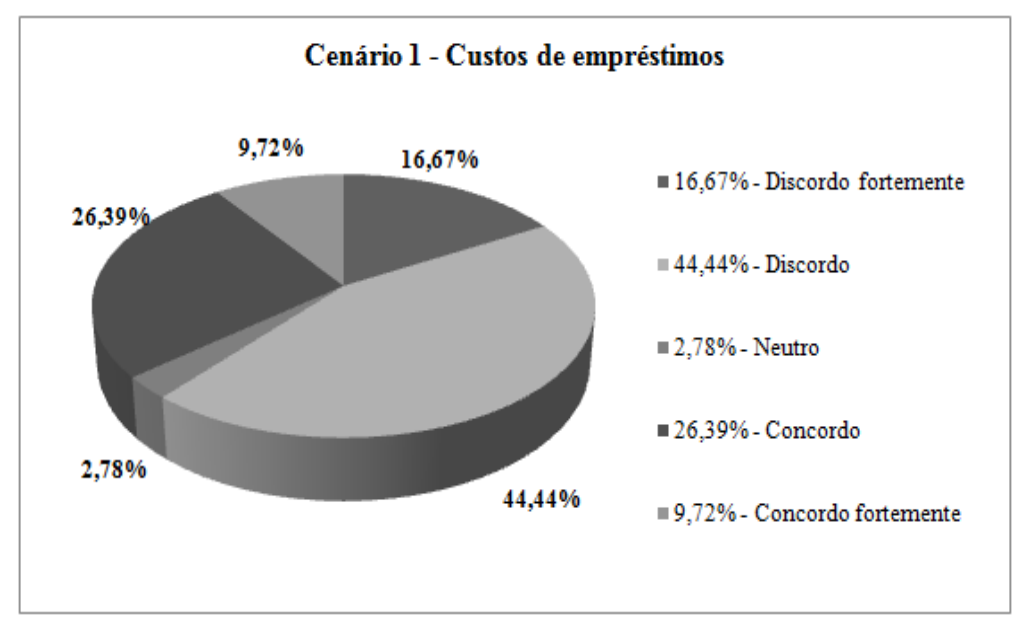

Figura 1. Interpretações do Cenário - Custos de Empréstimos.

As respostas sugeriram que, apesar de a maioria dos auditores terem discordado do encerramento da capitalização dos custos, $36,11 \%$ dos profissionais interpretaram que os itens faltantes para o término do bloco 1 (equivalentes a $5 \%$ das obras dessa parte) se enquadraram no conceito de modificações menores, citadas no CPC 20, e, portanto, concordaram com a finalização da capitalização dos custos dos empréstimos (Figura 1). Esses dados indicaram a existência de disparidades de tratamentos contábeis, referentes a uma situação pautada no CPC 20.

No segundo cenário, os auditores receberam informações sobre uma montadora de automóveis que detinha um montante considerável de tributos diferidos, e que teve prejuízos nos últimos três anos, decorrentes da instabilidade econômica oriunda da crise de 2008, do aumento da taxa de juros, da redução dos incentivos no setor e dos desastres naturais ocorridos no Japão, que provocaram a destruição dos seus principais fornecedores de peças.

O tratamento contábil que deveria ser dado ao ativo fiscal diferido não foi consenso entre dois contabilistas que trabalhavam na montadora. $\mathrm{O}$ primeiro contador afirmou: "Teremos que baixar uma parte do ativo fiscal diferido, pois não podemos afirmar que ele será totalmente compensado antes de sua expiração". Já o segundo assumiu uma posição contrária e discorreu: "Não, nós podemos manter o saldo na conta do ativo fiscal diferido, uma vez que ele será utilizado quando a empresa retornar ao seu nível normal de lucratividade".

O contraste identificado nas interpretações pautadas no CPC 20 também foi visualizado neste cenário (Figura 2). 


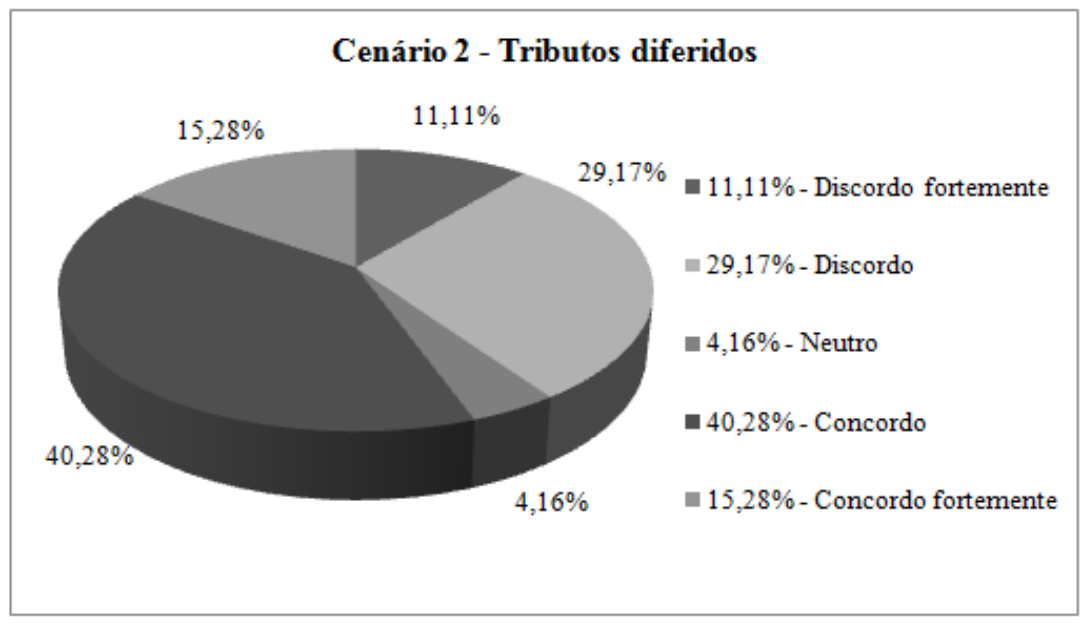

Figura 2. Interpretações do Cenário - Tributos Diferidos.

Esses dados indicaram que a maior parte dos auditores (40,28\% concordaram e 15,28\% concordaram fortemente) entendeu que a montadora deveria baixar parte do ativo fiscal diferido, em virtude da impossibilidade de se afirmar que tal montante poderia ser compensado, enquanto 40,28\% dos profissionais discordaram desse tratamento contábil.

No que tange ao terceiro cenário, os auditores se depararam com uma empresa que descartava resíduos no ambiente e que, como estava instalada em um país que não tinha legislação ambiental que determinasse a restauração dos impactos ambientais, nunca se preocupou em reparar os danos causados. Ainda assim, quinze dias antes do término do exercício social, a sua administração se comprometeu, em seu sítio, a adotar práticas de sustentabilidade e destacou que a probabilidade de desembolsar recursos para a limpeza dos resíduos que descartou era de $40 \%$ a $60 \%$.

No final do exercício social, dois contabilistas tiveram um conflito de opiniões quanto ao tratamento contábil da situação descrita, sendo que o primeiro profissional afirmou: "Nós necessitamos reconhecer uma provisão, referente ao valor da limpeza, nas demonstrações contábeis do final do exercício social". Já o segundo contabilista respondeu: "Não. Acredito que nós não devemos reconhecer uma provisão no final desse exercício".

Assim, pautados no CPC 25, os auditores deveriam expressar a sua concordância com o reconhecimento da provisão. Especificamente, os auditores deveriam interpretar se a divulgação do compromisso com a adoção de práticas de sustentabilidade originou uma obrigação não formalizada.

Ademais, os auditores deveriam averiguar se a saída de recursos era provável, pautados na informação referente à probabilidade, de $40 \%$ a $60 \%$, de desembolso de recursos para a limpeza dos resíduos. Para efeito, particularmente, do CPC 25, "uma saída de recursos ou outro evento é considerado como provável se o evento for mais provável que sim do que não de ocorrer, isto é, se a probabilidade de que o evento ocorrerá for maior do que a probabilidade de isso não acontecer" (CPC, 2009c, p. 10).

Assim, no cenário apresentado, cuja estimativa da probabilidade de saída de recursos não é exata (40\% a 60\%), poderia se esperar que os auditores ficassem neutros, em função da inexistência de um percentual pontual menor ou maior do que 50\%, conforme destacado no pronunciamento. Contudo, $81,95 \%$ dos auditores entenderam que a empresa necessitava reconhecer uma provisão, referente ao valor da limpeza, nas demonstrações contábeis do final do exercício social, enquanto apenas 12,50\% discordaram parcial ou fortemente de tal tratamento (Figura 3). 


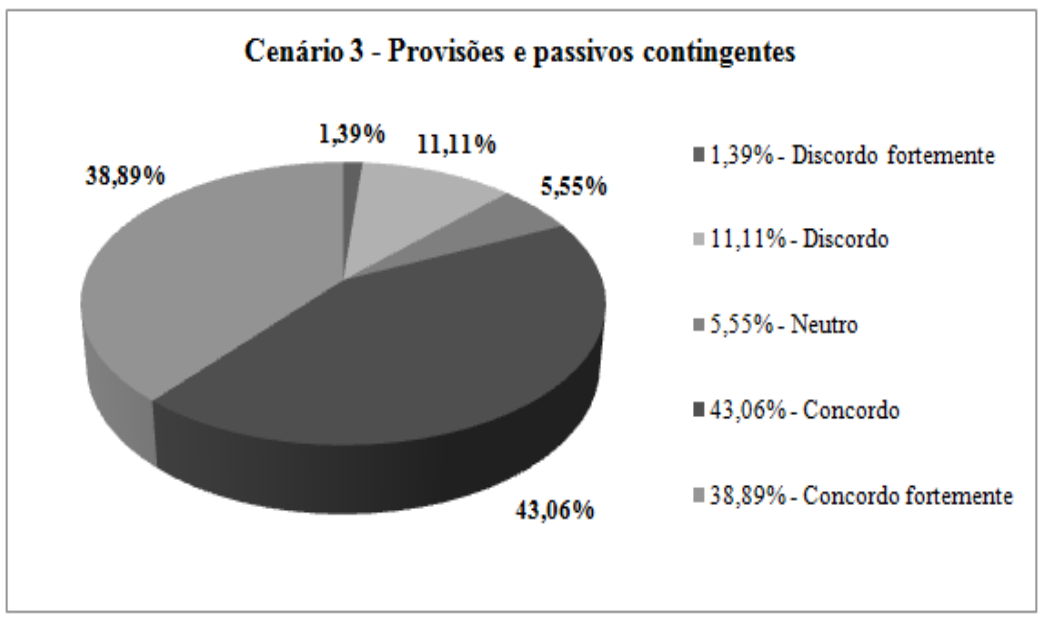

Figura 3. Interpretações do Cenário - Provisões e Passivos Contingentes.

Nota-se que a disparidade das opiniões foi pequena, quando comparada à visualizada nos dois primeiros cenários, o que denota que os tratamentos contábeis apontados pelos auditores, neste cenário, apresentaram maior semelhança.

No último cenário, os auditores se depararam com uma companhia que necessitou dos serviços de consultoria de uma empresa de pesquisa agrícola para desenvolver cepas, empregadas na produção da cana-de-açúcar, que fossem capazes de otimizar o processo produtivo. Em outras palavras, o objetivo era que tais cepas fossem resistentes às pragas e que, portanto, proporcionassem rendimentos mais elevados para a empresa. Após anos de pesquisa, alguns testes foram efetuados no exercício social em curso, e os resultados evidenciaram que as cepas produzidas foram resistentes às pragas e aumentaram a produção de açúcar.

Nesse cenário positivo, a empresa de consultoria destacou que não havia razões que impulsionassem a ideia de que os resultados encontrados não fossem obtidos em outras fazendas. Contudo, pelo fato de o açúcar ser considerado um produto com pouca diferenciação, nenhuma pesquisa de mercado foi realizada para verificar a aceitação do consumidor em relação ao novo açúcar.

Nesse caso, os dois contabilistas da empresa não tiveram opiniões iguais quanto ao tratamento contábil dos gastos anuais com o desenvolvimento das cepas. Um deles afirmou: "Nós mudamos para a fase de desenvolvimento deste projeto e as suas perspectivas são boas. Diante disso, nós podemos capitalizar as despesas deste ano". Já o segundo asseverou: "Não. Eu acho que nós ainda temos que considerar este trabalho como pesquisa. E, sendo assim, ainda devemos contabilizar os gastos deste ano como despesas".

O CPC 04 - Ativo Intangível instrui que, para o reconhecimento de um ativo intangível, em fase de desenvolvimento, a empresa necessita demonstrar todos os itens elencados no Pronunciamento, que incluem, dentre outros: a viabilidade técnica para concluir o ativo intangível de forma que ele seja disponibilizado para uso ou venda; a intenção de concluí-lo e de usá-lo ou vendê-lo; e a disponibilidade de recursos adequados para tanto, o que pode ser demonstrado, por exemplo, por intermédio de um plano de negócios.

Ademais, a organização necessita evidenciar a sua capacidade para usar ou vender o ativo intangível e a forma como o tal ativo deve gerar benefícios econômicos futuros. De forma geral, a empresa precisa provar que existe demanda para os produtos oriundos do ativo intangível ou para este ativo em si. Para os casos em que a empresa vá utilizá-lo internamente, ela precisa mostrar a sua utilidade. Assim, a Figura 4 aponta as interpretações dos auditores. 


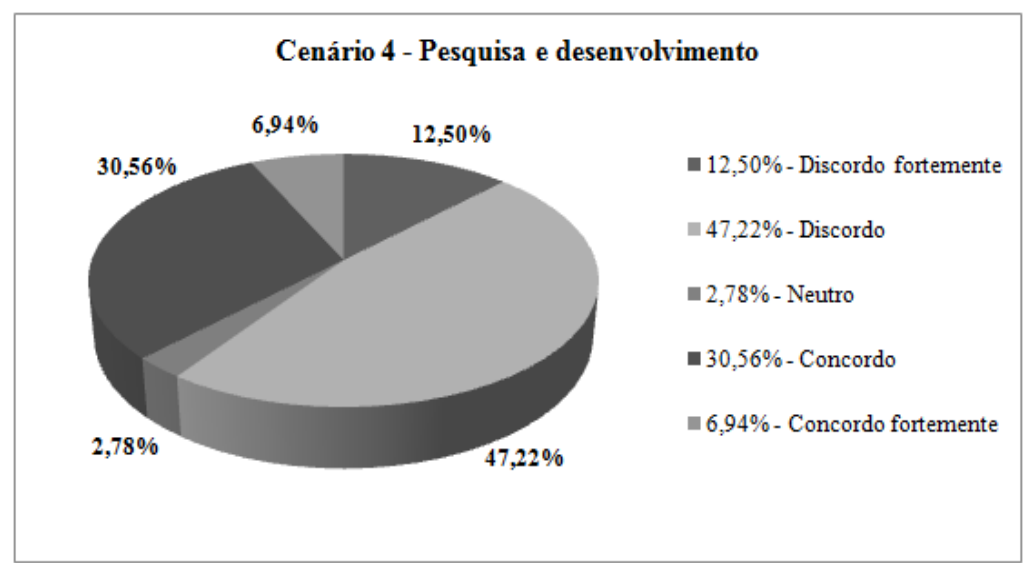

Figura 4. Interpretações do Cenário - Pesquisa e Desenvolvimento.

Percebe-se que, dentre os respondentes, $59,72 \%$ discordaram de que o projeto já estava na fase de desenvolvimento, o que indicou que eles julgaram que tal processo ainda deveria ser considerado uma pesquisa e que seus gastos eram despesas. Com opiniões contrárias, 37,50\% dos auditores concordaram em que os gastos do exercício social em questão referiam-se a um projeto em fase de desenvolvimento e que deveriam ser capitalizados (Figura 4).

De maneira geral, observou-se a existência de respostas díspares em todos os cenários, mas, em menor magnitude, no caso pautado no CPC 25 - Provisões, Passivos Contingentes e Ativos Contingentes (Tabela 2).

Tabela 2

\section{Resumo das Interpretações}

\begin{tabular}{lcccc}
\hline Interpretações dos CPCs & CPC 20 & CPC 32 & CPC 25 & CPC 04 \\
\hline Discordo fortemente & $16,67 \%$ & $11,11 \%$ & $1,39 \%$ & $12,50 \%$ \\
Discordo & $44,44 \%$ & $29,17 \%$ & $11,11 \%$ & $47,22 \%$ \\
Neutro & $2,78 \%$ & $4,16 \%$ & $5,55 \%$ & $2,78 \%$ \\
Concordo & $26,39 \%$ & $40,28 \%$ & $43,06 \%$ & $30,56 \%$ \\
Concordo fortemente & $9,72 \%$ & $15,28 \%$ & $38,89 \%$ & $6,94 \%$ \\
\hline
\end{tabular}

Além disso, percebeu-se que, em um nível de significância de 5\%, houve poucas associações entre as variáveis estudadas e as interpretações dos auditores (Tabela 3). Tais associações referiram-se às divergências de interpretações no cenário dos Tributos Diferidos, em vista do tamanho da empresa em que os auditores trabalhavam e da familiaridade com as Normas Internacionais de Contabilidade. 
Tabela 3

Resumo dos Testes Qui-quadrado

\begin{tabular}{|c|c|c|c|}
\hline Variável & $\begin{array}{l}\text { Teste Qui-quadrado - } \\
\text { Monte Carlo }\end{array}$ & Teste Qui-quadrado & $\begin{array}{c}\text { Aceite/Rejeição das } \\
\text { Hipóteses }\end{array}$ \\
\hline \multicolumn{4}{|c|}{ Custos de empréstimos } \\
\hline Tamanho da empresa & 0,601 & 0,602 & Aceite \\
\hline Familiaridade & 0,566 & 0,629 & Aceite \\
\hline Experiência em auditoria & 0,972 & 0,970 & Aceite \\
\hline Experiência em IFRS & 0,876 & 0,865 & Aceite \\
\hline \multicolumn{4}{|c|}{ Tributos diferidos } \\
\hline Tamanho da empresa & 0,011 & 0,014 & Rejeição* \\
\hline Familiaridade & 0,018 & 0,001 & Rejeição* \\
\hline Experiência em auditoria & 0,333 & 0,339 & Aceite \\
\hline Experiência em IFRS & 0,394 & 0,381 & Aceite \\
\hline \multicolumn{4}{|c|}{ Provisões e passivos Contingentes } \\
\hline Tamanho da empresa & 0,309 & 0,310 & Aceite \\
\hline Familiaridade & 0,548 & 0,733 & Aceite \\
\hline Experiência em auditoria & 0,348 & 0,400 & Aceite \\
\hline Experiência em IFRS & 0,085 & 0,083 & Rejeição** \\
\hline \multicolumn{4}{|c|}{ Pesquisa e desenvolvimento } \\
\hline Tamanho da empresa & 0,788 & 0,770 & Aceite \\
\hline Familiaridade & 0,060 & 0,024 & Rejeiçãa*** \\
\hline Experiência em auditoria & 0,256 & 0,237 & Aceite \\
\hline Experiência em IFRS & 0,082 & 0,069 & Rejeição** \\
\hline
\end{tabular}

Nota. * Nível de significância: 5\% ; ** Nível de significância: $10 \%$.

Sendo assim, percebe-se que, com exceção de duas variáveis analisadas no cenário dos Tributos Diferidos, não houve interpretações estatisticamente distintas entre os auditores, com a consideração de um nível de significância de $5 \%$.

Porém, destaca-se que os p-values dos Testes Qui-quadrado - Monte Carlo, com as variáveis: experiência profissional em atividades relacionadas às Normas Internacionais de Contabilidade (Cenários - Provisões e Passivos Contingentes e Pesquisa e Desenvolvimento); e a familiaridade com as IFRS (Cenário - Pesquisa e Desenvolvimento) indicaram que tais variáveis estavam associadas com as interpretações dos auditores com a consideração de um nível de significância de $10 \%$.

Essa associação indica que as interpretações dos auditores com distintos níveis de familiaridade com as IFRS, por exemplo, não foram estatisticamente semelhantes no cenário que abordou o Ativo Intangível (Pesquisa e Desenvolvimento). De forma análoga, as respostas dos auditores que tinham maior experiência profissional com as Normas Internacionais de Contabilidade foram estatisticamente distintas das respostas dos profissionais que tinham menor experiência com as referidas normas (Cenários - Provisões e Passivos Contingentes e Pesquisa e Desenvolvimento).

Observa-se ainda, na Tabela 3, que em todos os testes realizados, a decisão de rejeição ou aceite das hipóteses foi a mesma tanto com a utilização do Teste Qui-quadrado quanto com o emprego do 
Teste Qui-quadrado - Monte Carlo, o que reforça a consistência dos p-values identificados na pesquisa e, consequentemente, dos resultados obtidos por meio dos testes estatísticos.

As associações identificadas pelo Teste Qui-quadrado foram evidenciadas nos mapas perceptuais provenientes da ANACOR e da HOMALS. No cenário que abordou os Tributos diferidos é possível visualizar, por meio do mapa perceptual proveniente da técnica HOMALS, a associação entre o tamanho da empresa, os níveis de familiaridade com as IFRS e as interpretações dos auditores. Verifica-se, por exemplo, a associação tanto dos profissionais das Big Four quanto dos auditores com maior familiaridade ( 8 a 10) com a concordância com a baixa de parte do ativo fiscal diferido (Figura 5).

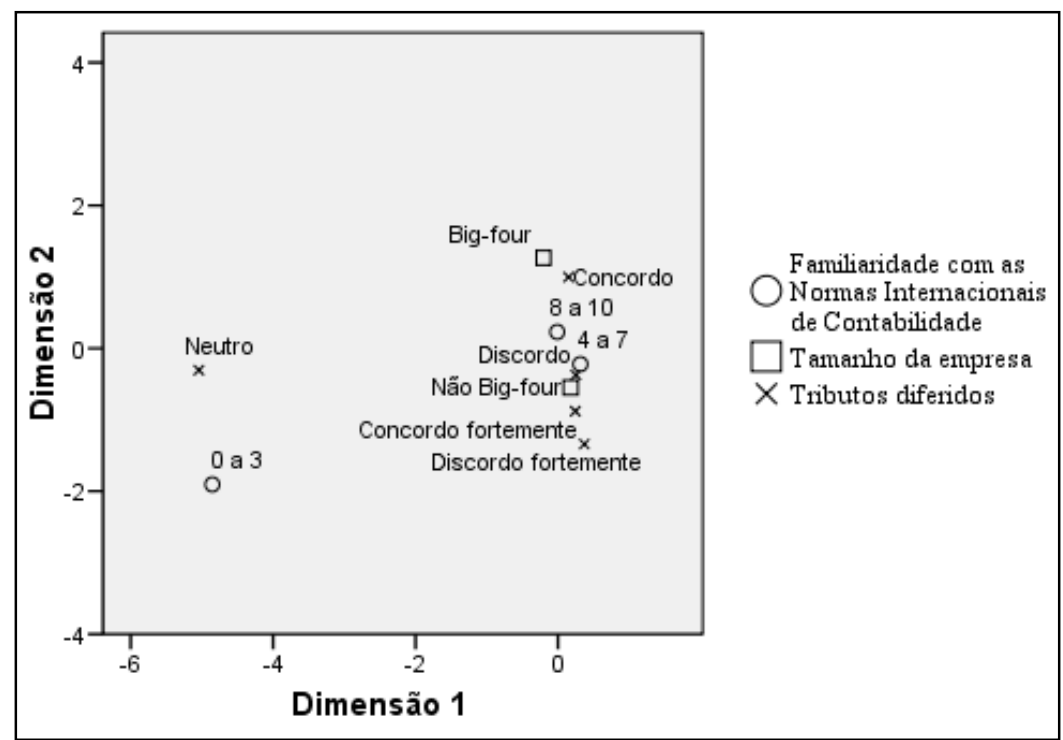

Figura 5. Mapa Perceptual (HOMALS) do Cenário - Tributos Diferidos.

O mapa perceptual também evidencia que o profissional com menor familiaridade com as IFRS (0 a 3) ficou neutro quanto à baixa de parte do ativo fiscal diferido.

No que diz respeito ao cenário que abordou as Provisões e Passivos Contingentes, aplicou-se a ANACOR, uma vez que apenas uma variável apresentou associação com as respostas dos auditores (Figura 6).

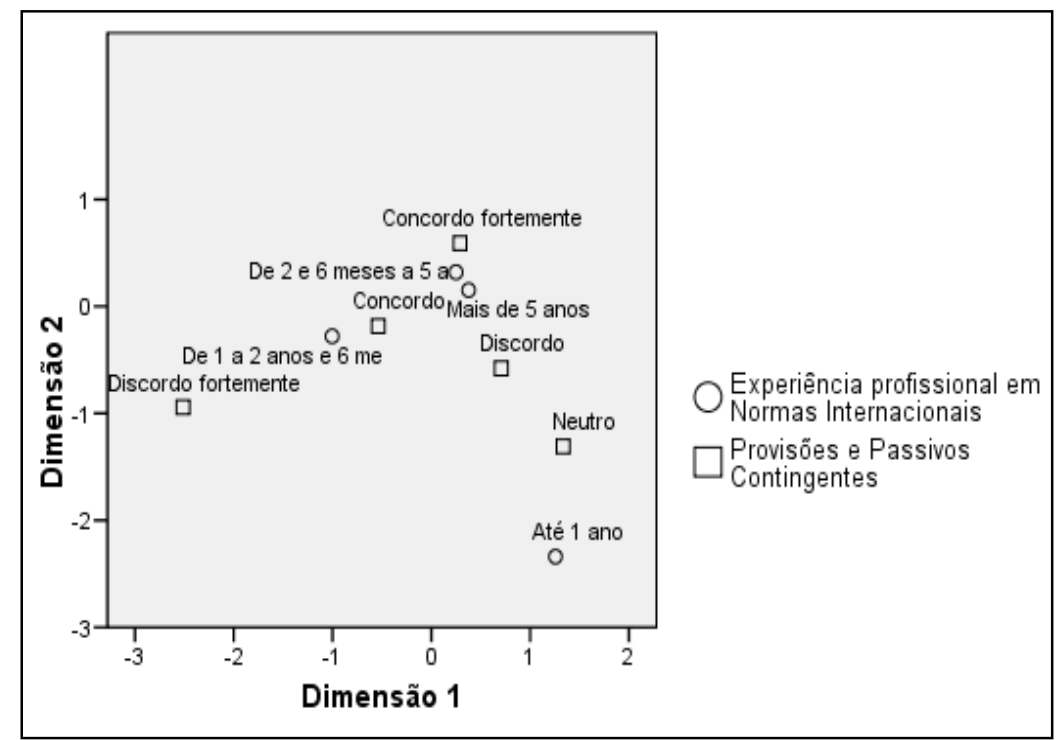

Figura 6. Mapa Perceptual (ANACOR) do Cenário - Provisões e Passivos Contingentes. 
Nota-se, na Figura 6, a existência de proximidade entre a concordância com o tratamento contábil apresentado nesse cenário e os profissionais com experiência: de um ano a dois anos e seis meses; de dois anos e seis meses a cinco anos; e de mais de cinco anos. Percebe-se também que, dentre os profissionais com experiência de dois anos e seis meses a cinco anos, a opção predominante refere-se a concordo fortemente.

Já o mapa perceptual apresentado na Figura 7 evidencia que os profissionais com maior experiência com as IFRS (mais de cinco anos), assim como os auditores com maior familiaridade com o tema (8 a 10), predominantemente, optaram pela opção de discordância do tratamento contábil apresentado.

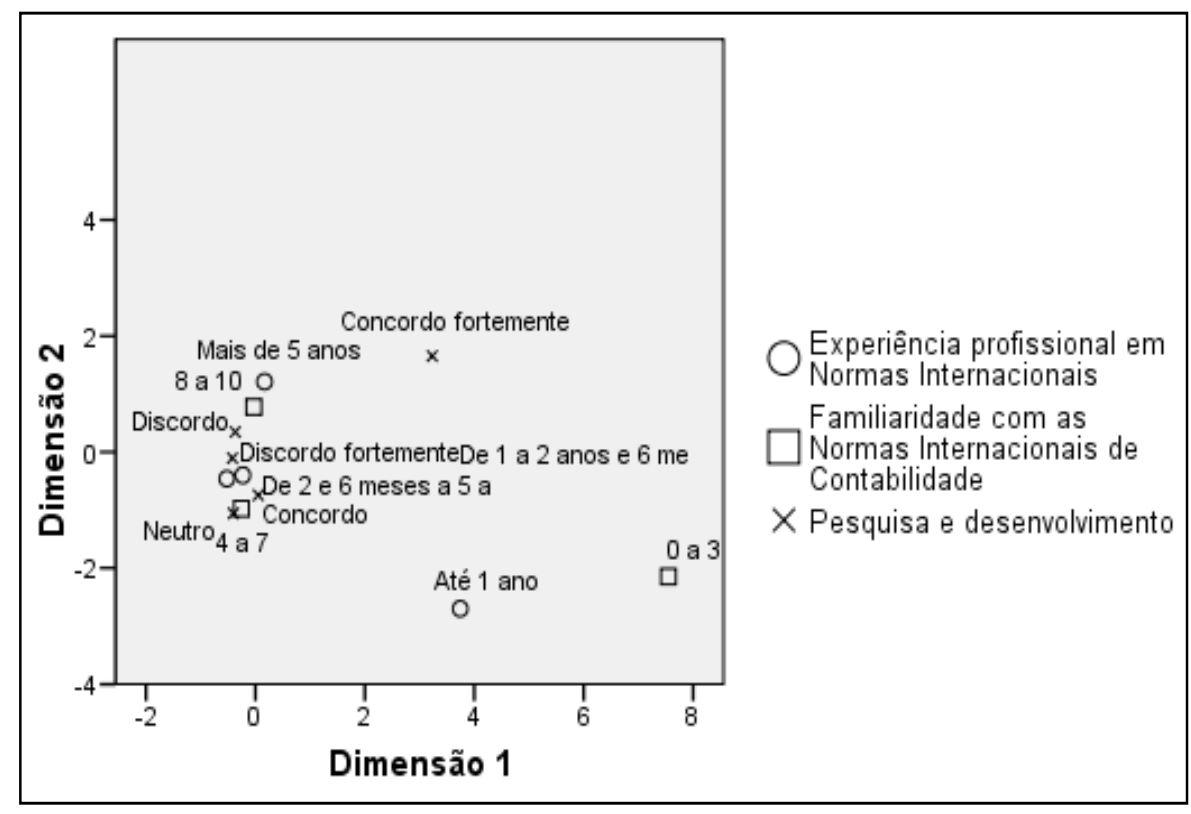

Figura 7. Mapa Perceptual (HOMALS) do Cenário - Pesquisa e Desenvolvimento.

Por outro lado, também é possível observar que os profissionais com experiência entre dois anos e seis meses e cinco anos, predominantemente, optaram pela opção concordo. Tais diferenças de opiniões também podem ser visualizadas na Tabela 4, que apresenta a existência de disparidades nas respostas predominantes dos auditores.

No cenário que abordou Pesquisa e Desenvolvimento, por exemplo, os profissionais com experiência em auditoria entre cinco e oito anos, predominantemente, optaram pela opção "concordo" com a contabilização, enquanto a opinião que prevaleceu dentre os auditores com maior experiência em auditoria (mais de 8 anos) foi a opção discordo (Tabela 4).

Tabela 4

Resumo das Respostas Predominantes - Escala Likert

\begin{tabular}{lccccc}
\hline Variáveis & $\begin{array}{c}\text { Categorias de } \\
\text { Análise }\end{array}$ & $\begin{array}{c}\text { Custos de } \\
\text { Empréstimos }\end{array}$ & $\begin{array}{c}\text { Tributos } \\
\text { Diferidos }\end{array}$ & $\begin{array}{c}\text { Provisões e } \\
\text { Passivos } \\
\text { Contingentes }\end{array}$ & $\begin{array}{c}\text { Pesquisa e } \\
\text { Desenvolvimento }\end{array}$ \\
\hline $\begin{array}{l}\text { Tamanho da } \\
\text { empresa }\end{array}$ & Big four & Discordo & Concordo & Concordo & Discordo \\
& Não Big four & Discordo & Discordo & Concordo & Discordo \\
& Total & Discordo & Concordo & Concordo & Discordo \\
\hline
\end{tabular}


Tabela 4 (continuação)

\begin{tabular}{|c|c|c|c|c|c|}
\hline Variáveis & $\begin{array}{c}\text { Categorias de } \\
\text { Análise }\end{array}$ & $\begin{array}{c}\text { Custos de } \\
\text { Empréstimos }\end{array}$ & $\begin{array}{l}\text { Tributos } \\
\text { Diferidos }\end{array}$ & $\begin{array}{c}\text { Provisões e } \\
\text { Passivos } \\
\text { Contingentes }\end{array}$ & $\begin{array}{c}\text { Pesquisa e } \\
\text { Desenvolvimento }\end{array}$ \\
\hline \multirow[t]{4}{*}{$\begin{array}{l}\text { Familiaridade } \\
\text { com as IFRS }\end{array}$} & 0 a 3 & Discordo & Neutro & Concordo & $\begin{array}{l}\text { Concordo } \\
\text { fortemente }\end{array}$ \\
\hline & 4 a 7 & Discordo & Concordo & Concordo & Discordo \\
\hline & 8 a 10 & Discordo & Concordo & $\begin{array}{l}\text { Concordo } \\
\text { fortemente }\end{array}$ & Discordo \\
\hline & Total & Discordo & Concordo & Concordo & Discordo \\
\hline \multirow{5}{*}{$\begin{array}{l}\text { Experiência em } \\
\text { atividades de } \\
\text { auditoria }\end{array}$} & Até 2 anos & Discordo & $\begin{array}{l}\text { Sem opinião } \\
\text { predominante }\end{array}$ & $\begin{array}{l}\text { Sem opinião } \\
\text { predominante }\end{array}$ & Concordo \\
\hline & De 2 a 5 anos & $\begin{array}{l}\text { Sem opinião } \\
\text { predominante }\end{array}$ & Concordo & $\begin{array}{l}\text { Sem opinião } \\
\text { predominante }\end{array}$ & Discordo \\
\hline & De 5 a 8 anos & Discordo & Discordo & $\begin{array}{l}\text { Concordo } \\
\text { fortemente }\end{array}$ & Concordo \\
\hline & Mais de 8 anos & Discordo & Concordo & Concordo & Discordo \\
\hline & Total & Discordo & Concordo & Concordo & Discordo \\
\hline \multirow{5}{*}{$\begin{array}{l}\text { Experiências em } \\
\text { atividades } \\
\text { relacionadas às } \\
\text { Normas } \\
\text { Internacionais }\end{array}$} & Até 1 ano & Discordo & $\begin{array}{l}\text { Sem opinião } \\
\text { predominante }\end{array}$ & $\begin{array}{l}\text { Sem opinião } \\
\text { predominante }\end{array}$ & Concordo \\
\hline & $\begin{array}{c}\text { De } 1 \text { ano a } 2 \\
\text { anos e } 6 \text { meses }\end{array}$ & Discordo & Concordo & Concordo & Discordo \\
\hline & $\begin{array}{l}\text { De } 2 \text { anos e } 6 \\
\text { meses a } 5 \text { anos }\end{array}$ & Discordo & Concordo & $\begin{array}{l}\text { Concordo } \\
\text { fortemente }\end{array}$ & Concordo \\
\hline & Mais de 5 anos & Discordo & Concordo & $\begin{array}{l}\text { Concordo } \\
\text { fortemente }\end{array}$ & Discordo \\
\hline & Total & Discordo & Concordo & Concordo & Discordo \\
\hline
\end{tabular}

Esse contraste de opiniões também pôde ser visualizado no cenário que abordou os Tributos Diferidos, em que, por exemplo, os auditores das Big four, predominantemente, apontaram a opção concordo com o tratamento contábil, enquanto os profissionais das demais empresas de auditoria adotaram uma postura de discordância.

Realça-se, ainda, a ausência de uma resposta predominante em cenários, como o que abordou os Custos de Empréstimos. Nesse caso, dentre os auditores com experiência em auditoria entre dois e cinco anos, 50\% discordaram e 50\% concordaram com a contabilização da situação (Tabela 4). Em suma, tais fatos indicam a existência de respostas conflitantes entre os auditores da amostra.

\section{Considerações Finais}

As ações dos países de diversas regiões do mundo para efetuar a convergência das suas normas ao Padrão Internacional aumentam com o passar dos anos. Tal cenário de mudança na área contábil, em que as melhores qualidade, confiabilidade e comparabilidade das informações entre os diversos países são consideradas metas primordiais, suscitou tanto o envolvimento dos órgãos reguladores e dos profissionais ligados à área contábil, quanto a inquietação de autores, no que concerne ao quão efetivo 
seria o processo de convergência contábil mundial, se as interpretações das Normas Internacionais de Contabilidade não fossem consistentes ou uniformes.

Em consonância com tais estudos, esta pesquisa teve o objetivo de identificar possíveis disparidades nas interpretações dos auditores independentes do Brasil, no que tange aos Pronunciamentos Contábeis emitidos pelo CPC.

$\mathrm{Na}$ análise descritiva dos dados, visualizou-se que as opiniões dos auditores em cada um dos casos não foram uniformes, isto é, houve disparidades em todos os quatro cenários. Sendo assim, buscou-se identificar, com base na literatura, variáveis que pudessem estar associadas aos díspares entendimentos das normas contábeis.

Para os testes estatísticos, utilizou-se o Teste Qui-quadrado, o Teste Qui-quadrado - Monte Carlo, a ANACOR e a HOMALS. Identificou-se que, com um nível de significância de 5\%, as variáveis tamanho da empresa e familiaridade estavam estatisticamente associadas com as interpretações dos auditores.

Destaca-se, ainda, que, com a consideração do nível de significância de $10 \%$, foi possível rejeitar todas as outras hipóteses, com exceção da que aborda a variável experiência em auditoria. Em outras palavras, as interpretações dos auditores, em alguns cenários, estavam associadas com as suas familiaridades com as Normas Internacionais de Contabilidade e com as suas experiências profissionais relacionadas às IFRS.

Esses resultados são coerentes com a pesquisa de Chand et al. (2010), que evidenciou a ocorrência de interpretações díspares dentre os profissionais que trabalham em empresas com tamanhos distintos.

Por conseguinte, as constatações desta pesquisa, pautadas especificamente em um instrumento simplificado, levantam indícios de uma possível falta de consenso nas interpretações dos Pronunciamentos Contábeis brasileiros, que já entraram em vigor no ano de 2010. O estudo da Ernst \& Young e da FIPECAFI (2011) identificou diferentes tratamentos contábeis nas demonstrações das empresas brasileiras. No mesmo sentido, este trabalho apontou que existe a possibilidade de interpretações díspares diante de situações pautadas nos Pronunciamentos Contábeis.

Acentua-se, ainda, que esta pesquisa não teve o intuito de explorar todos os aspectos pertinentes às interpretações dos auditores, mas levantar indícios de como tais profissionais interpretariam situações práticas simplificadas e hipotéticas que remeteriam ao entendimento de quatro Pronunciamentos Contábeis brasileiros. Destaca-se, novamente, a obtenção de um pequeno número de respostas, a existência de limitações no instrumento utilizado no trabalho e, consequentemente, a exigência de cuidado ao interpretar os resultados identificados nesta pesquisa.

Sugere-se, para pesquisas futuras, a utilização de cenários mais detalhados e que abordem outros Pronunciamentos Contábeis. Além disso, seriam pertinentes os estudos que visem verificar como os contabilistas, profissionais vitais para a contabilização e evidenciação das diretrizes inseridas no novo processo contábil brasileiro, interpretam os Pronunciamentos do CPC.

Outra abordagem conveniente refere-se à investigação de possíveis medidas para as melhores compreensão e aplicação do teor dos Pronunciamentos Contábeis brasileiros nas demonstrações financeiras das empresas do Brasil. 


\section{Referências}

Alali, F., \& Cao, L. (2010). International financial reporting standards - credible and reliable? An overview. Advances in Accounting Incorporating Advances in International Accounting, 26(1), 79 - 86. doi: 10.1016/j.adiac.2010.02.001

Almeida, M. C. (2003). Auditoria: um curso moderno e completo (6a ed.). São Paulo: Atlas.

Asare, S. K., \& McDaniel, L. S. (1996). The effects of familiarity with the preparer and task complexity on the effectiveness of the audit review process. The Accounting Review, 71(2), 139159. Recuperado de http://www.jstor.org/pss/248443

Baker, C. R., \& Barbu, E. M. (2007). Trends in research on international accounting harmonization. The International Journal of Accounting, 42(3), 272-304. doi: 10.1016/j.intacc.2007.06.003

Bhattacharjee, S., \& Moreno, K. (2002). The impact of affective information on the professional judgments of more experienced and less experienced auditors. Journal of Behavioral Decision Making, 15(4), 361-377. doi: 10.1002/bdm.420

Bonner, S. E. (1990). Experience effects in auditing: the role of task-specific knowledge. The Accounting Review, 65(1), 72-92. Abstract. Recuperado de http://www.jstor.org/pss/247877

Carvalho, L. N., Lemes, S., \& Costa, F. M. (2008). Contabilidade internacional: aplicação das IFRS 2005. São Paulo: Atlas.

Chand, P., Patel, C., \& Day, R. (2008). Factors causing differences in the financial reporting practices in selected South Pacific countries in the post-convergence period. Asian Academy of Management Journal, 13(2), 111-129.

Chand, P., Patel, C., \& Patel, A. (2010). Interpretation and application of "new" and "complex" international financial reporting standards in Fiji: implications for convergence of accounting standards. Advances in Accounting, 26(2), 280-289. doi: 10.1016/j.adiac.2010.08.004

Choo, F., \& Trotman, K. T. (1991). The relationship between knowledge structure and judgments for experienced and inexperienced auditors. The Accounting Review, 66(3), 464-485.

Comitê dos Pronunciamentos Contábeis. (2009a). Pronunciamento Técnico CPC 20. 2009. Recuperado de http://www.cpc.org.br/pdf/CPC20_R1.pdf

Comitê dos Pronunciamentos Contábeis. (2009c). Pronunciamento Técnico CPC 25. Junho, 2009. Recuperado de http://www.cpc.org.br/pdf/CPC_25.pdf

Comitê dos Pronunciamentos Contábeis. (2009b). Pronunciamento Técnico CPC 32. Julho, 2009. Recuperado de http://www.cpc.org.br/pdf/CPC_32.pdf

Comitê dos Pronunciamentos Contábeis. (2010). Pronunciamento Técnico CPC 04 (R1). Novembro, 2010. Recuperado de http://www.cpc.org.br/pdf/CPC04_R1.pdf

Doupnik, T. S., \& Richter, M. (2003). Interpretation of uncertainty expressions: a cross-national study. Accounting, Organizations and Society, 28(1), 15-35. doi: 10.1016/S0361-3682(02)00010-7

Ernst \& Young, \& Fipecafi. (2011). IFRS: $1^{\circ}$ ano análises sobre a adoção inicial do IFRS no Brasil. Recuperado de http://mrm.comunique-se.com.br/arq/121/arq_121_219638.pdf

Farah, P. L. S., \& Ricardino, A. (2010). IAS 23 - Custos de empréstimos. In Ernst \& Young; FIPECAFI (Org.), Manual de normas internacionais de contabilidade: IFRS versus normas brasileiras (2a ed., pp. 245-251). São Paulo: Atlas. 
Fávero, L. P., Belfiore, P., Silva, F. L., \& Chan, B. L. (2009). Análise de dados: modelagem multivariada para tomada de decisões. Rio de Janeiro: Elsevier.

Fernandes, B. V. R., Lima, D. H. S., Vieira, E. T., \& Niyama, J. K. (2011). Análise da percepção dos docentes dos cursos de graduação em Ciências contábeis do Brasil quanto ao processo de convergência às normas internacionais de contabilidade aplicadas no Brasil. Revista de Contabilidade e Controladoria, 3(3), 24-50.

Fogarty, T. J., Hussein, M. E. A., \& Ketz, E. J. (1994). Political aspects of financial accounting standard setting in the USA. Accounting, Auditing \& Accountability Journal, 7(4), 24-46.

Franco, H., \& Marra, E. (2001). Auditoria contábil. São Paulo: Atlas.

Hoog, W. A. Z., \& Carlin, E. L. B. (2009). Manual de auditoria contábil. Curitiba: Juruá.

International Accounting Standards Board. (2012). Relatório quem somos e o que fazemos. Recuperado de http://www.ifrs.org/Theorganisation/Documents/WhoWeAre_Portuguese_2012.pdf

Instituto dos Auditores Independentes do Brasil. (2011). Ibracon: quatro décadas a serviço da auditoria. Revista Transparência, 1(4), 1-52. Recuperado de http://www.ibracon.com.br/ibracon/Portugues/detRevistaTransparencia.php?cod=7

Lei $n^{\circ} 4.728$, de 14 de julho de 1965. (1965). Disciplina o mercado de capitais e estabelece medidas para o seu desenvolvimento. Brasília, DF: Planalto. Recuperado de http://www.planalto.gov.br/ccivil_03/leis/L4728.htm

Lei $n^{\circ}$ 6.385, de 07 de dezembro de 1976. (1976). Dispõe sobre o mercado de valores mobiliários e cria a comissão de valores mobiliários. Brasília, DF: Planalto. Recuperado de http://www.planalto.gov.br/ccivil_03/leis/L6385.htm

Lei $n^{\circ}$ 6.404, de 15 de dezembro de 1976. (1976). Dispõe sobre as sociedades por ações. Brasília, DF: Planalto. Recuperado de http://www.planalto.gov.br/ccivil_03/leis/16404consol.htm

Lei $n^{\circ} 11.638$, de 28 de dezembro de 2007. (2007). Altera e revoga dispositivos da Lei ${ }^{\circ} 6.404$, de 15 de dezembro de 1976, e da Lei $n^{\circ} 6.385$, de 7 de dezembro de 1976, e estende às sociedades de grande porte disposições relativas à elaboração e divulgação de demonstrações financeiras. Brasília, DF: Planalto. Recuperado de http://www.planalto.gov.br/ccivil_03/_ato20072010/2007/lei/111638.htm

Levine, D. M., Stephan, D. F., Krehbiel, T. C., \& Berenson, M. L. (2008). Estatística: teoria e aplicações. Rio de Janeiro: LTC.

Nannini, L. C., \& Salotti, B. M. (2010). IAS 37 - Provisões, passivos contingentes e ativos contingentes. In Ernst \& Young; FIPECAFI. (Org.), Manual de normas internacionais de contabilidade: IFRS versus normas brasileiras (2a ed., pp. 357-368). São Paulo: Atlas.

Niyama, J. K. (2008). Contabilidade internacional. São Paulo: Atlas.

Niyama, J. K., \& Silva, T. (2009). Teoria da contabilidade. São Paulo: Atlas.

Nobes, C. (2006). The survival of international differences under IFRS: towards a research agenda. Accounting and Business Research, 36(3), 233-245. Recuperado de http://www.tandfonline.com/doi/abs/10.1080/00014788.2006.9730023. doi: $10.1080 / 00014788.2006 .9730023$

Pavese, F., \& Forbes, A. B. (2008). Data modeling for metrology and testing in measurement science. Recuperado 
http://books.google.com.br/books?id=61j6FZCJo0IC\&printsec=frontcover\&dq=Data+Modeling +for+Metrology+and+Testing+in+Measurement+Science\&hl=pt-BR

Piot, C., Dumontier, P., \& Janin, R. (2010). IFRS consequences on accounting conservatism within Europe. Recuperado de http://ssrn.com/abstract=1754504

Raimundini, S. L., Bianchi, M., Santos, N. A., Fávero, L. P. L., \& Schmidt, P. (2009). Percepções sobre o ensino da contabilidade introdutória para não contadores: a perspectiva dos discentes das Universidades Federais do estado do Rio Grande do Sul. Revista de Educação e Pesquisa em Contabilidade, 3(3), 85-105.

Samaha, K., \& Hegazy, M. (2010). An empirical investigation of the use of ISA 520 "analytical procedures" among Big 4 versus non-Big 4 audit firms in Egypt. Managerial Auditing Journal, 25(9), 882-911. doi: 10.1108/02686901011080053

Schmidt, P., Santos, J. L., \& Fernandes, L. A. (2004). Contabilidade internacional avançada. São Paulo: Atlas.

Schultz, J. J., Jr, \& Lopez, T. J. (2001). The impact of national influence on accounting estimates: Implications for international accounting standard-setters. The International Journal of Accounting, 36(3), 271-290. doi: 10.1016/S0020-7063(01)00103-0

Souza, A. J., de., \& Cardoso, R. L. (2012, julho). Impactos da adoção dos IFRS na perícia criminal. Anais do Congresso USP de Controladoria e Contabilidade, São Paulo, SP, Brasil, 12. Recuperado de http://www.congressousp.fipecafi.org/artigos122012/526.pdf

Tsalavoutas, I., \& Evans, L. (2010). Transition to IFRS in Greece: financial statement effects and auditor size. Managerial Auditing Journal, 25(8), 814-842. doi: 10.1108/02686901011069560

Zeff, S. A. (2007). Some obstacles to global financial reporting comparability and convergence at a high level of quality. The British Accounting Review, 39(4), 290-302. doi: 10.1016/j.bar.2007.08.001 